\title{
THE CHALLENGE IN INTERNAL COMBUSTION DIESEL ELETRONIC ENGINES IN A COMPETITIVE MARKET USING GLOBAL SUPPLIERS SOURCES.
}

\author{
André Sperl \\ Leandro Lafiandre Nahas \\ Mário Luiz Lima Trevizan \\ MWM Motores Diesel \\ E-mails: andre.sperl@ navistar.com.br, leandro.nahas@ navistar.com.br, \\ mario.trevizan@ navistar.com.br
}

\begin{abstract}
The product development has been a process even more critical for the competitiveness of the companies, increasing the diversity and variety of sourcing and products in contrast with a constant outdated industrial machinery due to the lack of substantial investments.

The process of product development is a interface between companies and market - then its strategic importance - with the function to develop a product that meets the market expectancies in terms of performance, emissions legislation and product total quality. This converges with a product development in reasonable time, faster than the opponents and with competitive design cost. The aim of this work consists in presenting a methodology of manufacturability analysis, considering the restrictions of costs, sourcing tolerances and production quality.
\end{abstract}

\section{INTRODUCTION}

Internal combustion engines are applied in light and heavy duty vehicles, where diesel engines with electronic injection system are included, these engines must have to be calibrated aiming to achieve performance i.e. power, torque and specific fuel consumption according to customer needs, in terms of the vehicle that it will be fitted. Also it must attend emissions limits of the legislation accordingly to the market needs where this vehicle is intended to be manufactured and consequently sold.

With the huge competitiveness on the internal combustion engines market, the global sourcing reality today is a common practice, engines can be developed in one side of the world and manufactured and sold in another as far as suppliers are spread worldwide. For instance turbochargers, fuel injection system and camshafts are key components that influence in engine calibration and combustion and can be developed in different parts of the world and work together in the same diesel engine.

Key components like these and its manufacturing tolerances influences on diesel engine combustion this could lead to variations in its performance and emissions, higher then legislation standards allowance. To avoid unsatisfied customers and after sales issues, there is a way to forecast performance and emissions of an engine using some tests and statistical 
tools to determine the maximum allowable hardware (i.e. parts) tolerances, to ensure that the performance and emissions targets will be reached and kept inside legislation limits for serial production of this engine. Needless to say that these tools are mandatory today in diesel engine development.

The aim of this work is to present a applied methodology using this existing tools to consider engine components variations influences on engine calibration and combustion, in order to meet performance and emissions to the market which it is intended to be sold.

Among these solutions we can mention the modeling statistic tools like the Design of Factorial Experiments and Response analysis.

The basic principles of the Design of Experiments- DoE - method have been known for a long time and have been investigated thoroughly. The roots of the DoE method were found in 1920s and, in part, even reach back to Carl Friedrich Gauss [2].

The first concepts of Planning Experiments were carried out in 1920 by Ronald Fisher in London, England and applied in agriculture. The interaction between Fisher and other researchers and scientists from different areas has spurred arise the concepts that led to three basic principles of planning Experiments: randomization, replication and blocks [1].

Fisher systematically introduced thoughts and statistical principles in their experimental investigations, including the concept of factorial experiment and analysis variance. In the two books he published in 1958 and 1966, both have deep influence on the use of statistics in agricultural experimentation. However, applications of Design of Experiments (DoE) in the industry certainly began in the mid-1930s, where the industrial era was marked by the development of methodology of Response Surface (RSM - Response Surface Methodology) by Box and Wilson. For over 30 years, Factorial Design of Experiments and Surface Response were spread in the chemical industries and manufacturing processes, mostly for research and product development. George Box was the intellectual leader of this movement [1].

In 1970, the increased interests of industries to improve quality, led to a new era of the Design of Experiments. The work of Genichi Taguchi had a significant impact on expanding the use of the methodology [1]. Taguchi suggested the use of the Design Factorials Fractionation and other orthogonal combinations to solve the problems, but at that time, due to the lack of statistical basis, this methodology generated so much discussion and controversy, all these lead to further expansion in the 1980s [1],[2]. Computer calculations development helped many new techniques to be developed in 1990s and 2000s that now they are widely used in various areas such as the financial sector, government operations, chemical industry, automotive industry and many others sectors. Figure 1 gives an overview of the most important historical development steps of it. [2] 


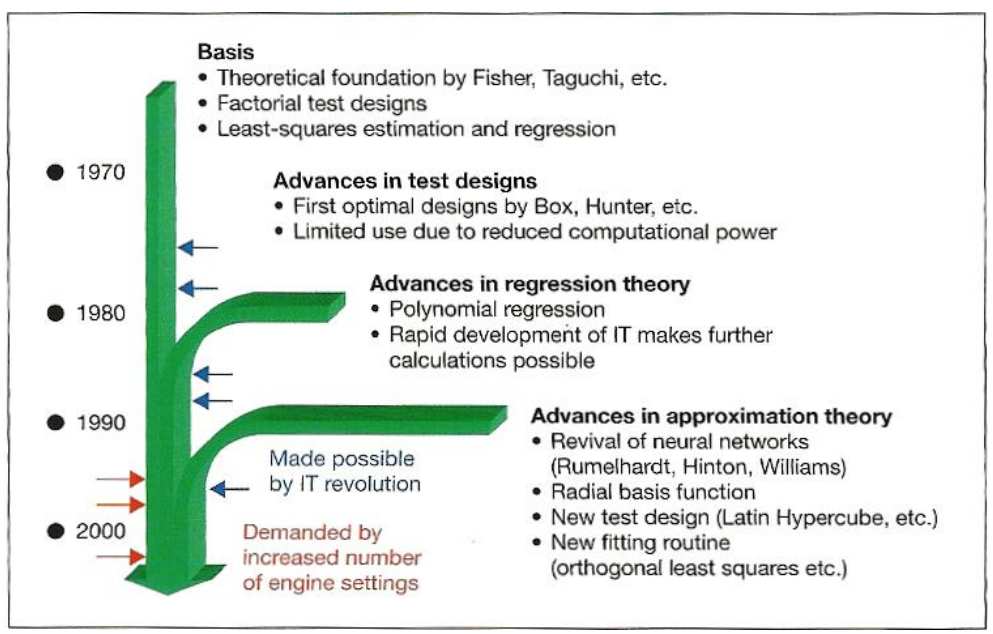

Figure 1 - Historic milestones of DoE [2].

\section{BACKGROUND}

\subsection{Design of Experiments - Basic Concepts}

Certain terms are extensively used in Design of Experiments field, among them we can mention response variable, an observed variable or measured in a experiment, meaning the result of the experiment. An experiment may have one or more response variables; it should be effective to quantify the desired results. Also the factors must be mentioned, which are the variables that suffer changes during an experiment, this means that this changes are done in a controlled manner with the objective of observe and evaluate the impact of them over the response variable. A factor can be qualitative or quantitative. Pressure, and injector hydraulic flow are quantitative factors meanwhile a certain type of piston or connecting rod are qualitative factors.

During the planning of a experiment, some methods can be used to identify the factors. Among them the most important can be highlighted: process mapping, scientific theories, engineering knowledge, team experience, brainstorming and cause and effect diagram known as Ishikawa.[1]

Factors suffer variations in their values and those variations are called levels. The level can be associated with points on a numerical scale by a quantitative factor or a specific option of a factor qualitative included in the experiment. Examples of levels for quantitative factors we can mention $100 \mathrm{MPa}$ or $160 \mathrm{Mpa}$ to injection pressure and type of piston A or B for qualitative factors.[1]

During the levels selection, some errors can be done like the selection of levels very close or far between them. Also during the experiment, some variables cannot be totally controlled by the researcher, and to these variables we call noise variables. The noise variables can affect a response variable in a experiment, still they are not interest as a factor, as examples we can mention temperature and relative humidity. The effects of noise variables can be minimized. Basically there are two ways to minimize 
them, keeping them constant or measuring them and take into account its effects during the analysis of the response variables.

It's important to have a well-designed experiment, because the results and conclusions that can be drawn from it usually depend on the way data was collected. In general, experiments are used to study the behavior of a process or system. The process or system can be represented by the model shown in Figure 2. Typically the process can be viewed as a combination of operations, machines, methods, people and other resources that turn a input into an output. Some variables such as $\mathrm{x}_{1}, \mathrm{x}_{2}, \ldots, \mathrm{x}_{\mathrm{p}}$ are controllable, while others like $\mathrm{z}_{1}, \mathrm{z}_{2}, \ldots, \mathrm{z}_{\mathrm{p}}$ are not controllable, but these for the purposes of test must be controlled in order to reduce noise during measurements.[5]

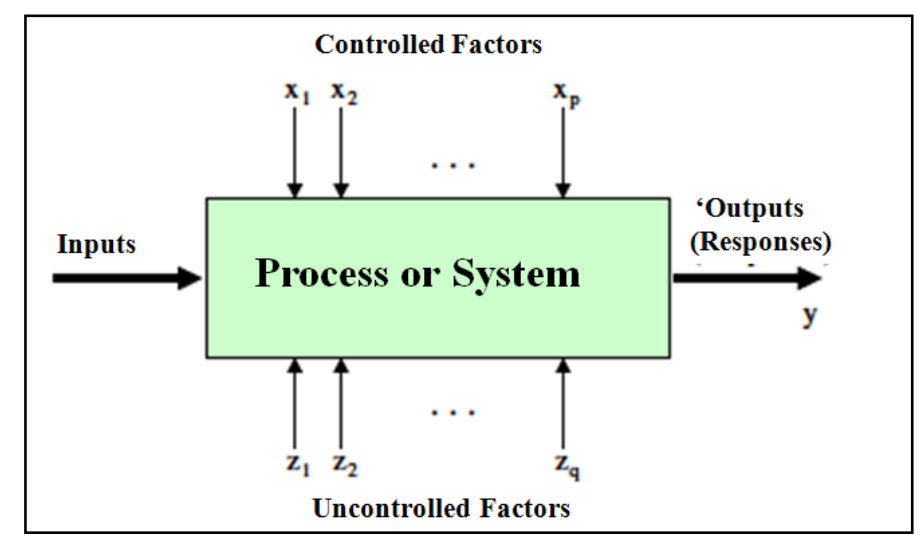

Figure 2 - General model of a process or system [1].

Literally, an experiment is nothing more than a test. Formally, we can define an experiment as a test or series of tests in which purposeful changes are made to input variables (factors) of a process or system and we can observe and identify the consequences of these changes in output variables (Response variables).

\subsubsection{Basic Principles}

If in an experiment is desired to obtain efficient results, a scientific strategy should be applied during the design of the experiment. The reference to statistical design of experiments is to the planning process where the appropriate data are collected (sampled) and can be analyzed using statistics methods, resulting in valid and objective conclusions. When the problem under analysis involves data with the possibility of experimental error, statistical methods are the only way to perform the analysis. However, there are two aspects applied to any experimental problem: design of experiments and statistical analysis of data.[1]

These two aspects are totally related because the method of analysis depends directly on the planning/design or strategy used. The three basic principles of Design of Experiments are: randomness, replica and blocks. [5]

Randomness is the basis for statistical methods in the Design of Experiments. It's understood by randomness when the location of the study material and the 
order in which the individual will develop the experiment are determined randomly, that means not following a predetermined sequence. [1]

Some software's such as Minitab, SPSS and others, are widely used in the selection and creation of Design of Experiments. This software's usually show the combinations of the Design of Experiments randomly. This random order or sequence is created using a random number generator. [4]

Replica is the suitability of some combinations of certain factors, with two important characteristics: first, it allows the researcher to obtain an estimate of the experimental error. This estimate experimental error becomes a important tool to determine whether a observed difference in a particular combination is really a statistical difference or if it was only caused by some measurement noise. The second, if the average sample (y) is used to estimate the true average response for one of the levels of a particular factor in an experiment, the replica allows the researcher to obtain a more accurate estimate of this parameter. This means, if $\sigma^{2}$ is the variance for a individual observation and there are $n$ replicas, then the variance of the sample mean can be written according to equation 1.[1]

$$
\sigma_{y}^{2}=\frac{\sigma^{2}}{n}
$$

\section{(Equation 1).}

Normally when the combinations in a given experiment were generated randomly, two or more consecutive combinations may have exactly the same levels for some of the factors. For example, let's suppose an experiment with three factors: Start of main injection, pre-injection start pressure and injection. When we use random combinations, see the following table 1 :

\begin{tabular}{c|c|c|c}
$\begin{array}{c}\text { Combination } \\
(-)\end{array}$ & $\begin{array}{c}\text { Fuel injector } \\
\text { hidraulic flow } \\
\text { (30ml/30sec) }\end{array}$ & $\begin{array}{c}\text { Engine } \\
\text { Syncronism } \\
\text { (ㅇ CRK) }\end{array}$ & $\begin{array}{c}\text { Nozzle tip } \\
\text { protusion -NTP } \\
\text { (injector high) } \\
\text { (mm) }\end{array}$ \\
\hline $\mathrm{i}$ & 490 & 12 & 0,7 \\
\hline $\mathrm{i}+1$ & 490 & 15 & 1,2 \\
\hline $\mathrm{i}+2$ & 510 & 15 & 1,2 \\
\hline
\end{tabular}

\section{Table 1 - Example experiment with random combinations}

Note that between the combinations $\mathrm{i}$ and $\mathrm{i}+1$ levels of fuel injector hydraulic flow are identical and between the combinations $i+1$ and $i+2$ the levels of engine synchronism and nozzle tip protrusion - NTP are identical. To obtain a true replica the researcher needs to change the NTP values for a intermediate between $i$ and $i+1$ combinations and similarly, the fuel injector hydraulic flow and engine syncronism changed to an intermediate configuration between the combinations $\mathrm{i}+1$ and $\mathrm{i}+2$. Part of the experimental error can be attributed to the variability associated with similar levels during the experiments. 
There is a big difference between replica and repetitions. For instance, suppose in a vehicle according to a special feature, the fuel consumption measurement was performed three times. These measurements are not replicas, but a way to repeat the measurements and in this case, the observed variation is a direct reflex of the measurement process or the system.Replicas reflects sources of variation both between various combinations of an experiment and between them.

Blocks are the design of experiments technique used to increase the accuracy of comparative made between factors of interest. Typically blocks are used to reduce or eliminate the variability transmitted by factors called "complicated", which are just factors that may influence in experiment response variables in a way that we are not directly interested. For example, when evaluating the fuel consumption in two vehicles of the same brand and model that would be considered identical, but in the truth may have slightly differences between each other due to some tolerances in the manufacturing process - and if we are not interested in evaluating these effects caused by these small differences, this factor's been seen as a "complicated" factor. In this case applies the methodology of blocks and the researcher typically divides the analysis of data blocks, thus avoiding errors in the conclusions.

\subsection{Factorial Planning}

Many experiments consider the study of the effects of two or more factors. In factorial experiments, all possible combinations of factor levels are investigated this case the experiment given the name full factorial. For example, if there are levels of $a$ factor A and $b$ levels of a factor $\mathrm{B}$, each replica contains all combinations $a b$. When the factors follow an arrangement according to a factorial design strategy, they are often called crossed arrangements.

The effect of a factor is defined as a change in a particular response variable produced by a change in a level of this factor. This is called main effect because it refers to main or key factors in a experiment. For instance, if we consider a simple experiment, a factorial design experiment with two factors with two levels for each factor, we call these levels of "low" and "high" and are indicated by "-" and "+" respectively. The main effect of factor A in this experiment can be understood as the difference between the mean response of the level "low" of the factor A and the average response of the level "high" of the factor B, as shown in Figure 3. [3]

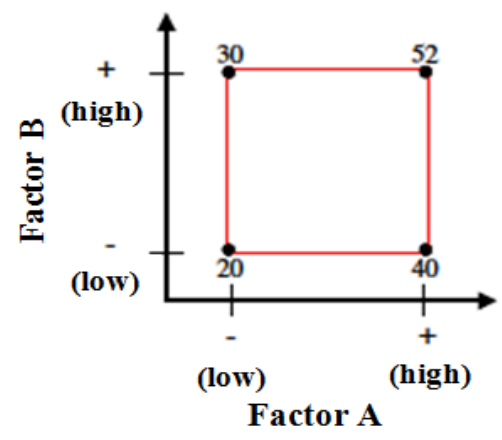

Figure 3 - factorial experiment with two factors with their response variables (y) displayed in square ends. 
Numerically we have [1]:

$$
A=\frac{40+52}{2}-\frac{20+30}{2}=21
$$

(Equation 2).

That is, increasing the A factor of "low" level for "High" level will have an average increase in the variable 21 response units. And similarly, for the purpose factor B we have [1]:

$$
B=\frac{30+52}{2}-\frac{20+40}{2}=11
$$

(Equation 3).

In some experiments we can find that the differences in response variables between the levels of a factor they are not the same for all levels of another factor. When this occurs, we can say that there is interaction between the factors. For example, considering the experiment factorial design with two factors shown in Figure 4, the level "Low" factor B $\left(\mathrm{B}^{-}\right)$, the effect of A would be [1]:

$$
\mathrm{A}=50-20=30 \text { (Equation 4). }
$$

And in the "high" level of the factor B $\left(\mathrm{B}^{+}\right)$, the effect of A would be:

$$
\mathrm{A}=12-40=-28 \text { (Equation 5). }
$$

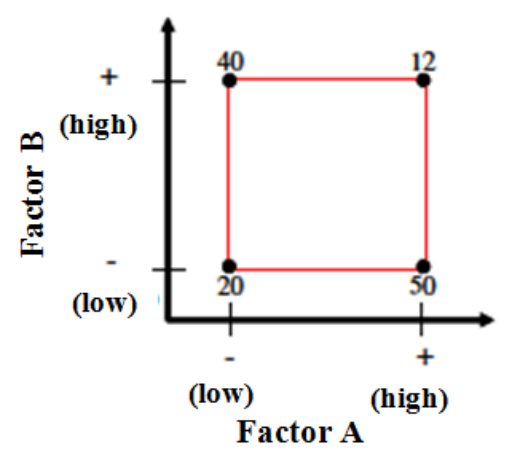

Figure 4 - factorial experiment with two factors, with their response variables (y) displayed in Quad ends with interactions.

As the effect of A depends on the chosen level of factor B, we can see that there is interaction between A and B [1]. The magnitude of the interaction effect is the average difference between these two effects, namely:

$$
A B=\frac{(-28-30)}{2}=-29
$$

(Equation 6).

These concepts can be graphically shown; as Figure 5 illustrates the data of the response variables from the experiment earlier described in Figure 3, factor A for the two levels of factor $\mathrm{B}$. In Figure 5 , lines $\mathrm{B}^{-}$and $\mathrm{B}^{+}$are parallel, indicating no 
interaction between Factors A and B. However, Figure 6 shows data of the response variables in experiment previously shown in Figure 4, but now the B- and B + lines are not parallel, indicating interaction between the factors $\mathrm{A}$ and $\mathrm{B}$.

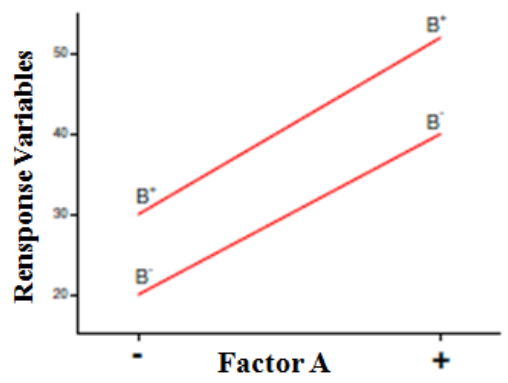

Figure 5 - Factorial experiment without interaction.

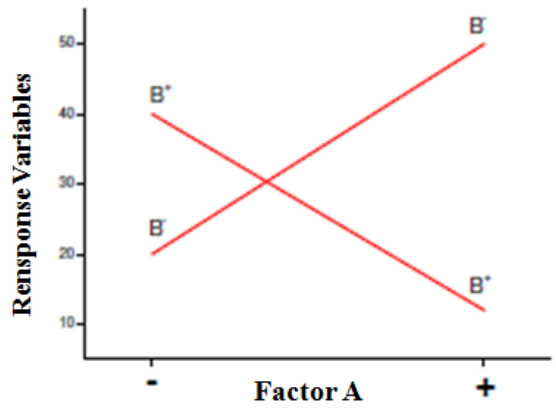

Figure 6 - Factorial experiment with interaction.

Graphical interactions between two factors as the above charts are very useful for the interpretation of interactions but they should not be used as the only technique for data analysis because their interpretation is subjective and can lead to an error [5].

There is another way to illustrate the concept of using a representation through interaction model regression where, for the two factors mentioned in previous charts we would have [3]:

$$
y=\beta_{0}+\beta_{1} x_{1}+\beta_{2} x_{2}+\beta_{12} x_{1} x_{2}+\varepsilon \text { (Equation 7). }
$$

Then $\mathrm{y}$ is the response variable, the $\beta s$ are the parameters whose values are determined, $\mathrm{x}_{1}$ is the variable that represents the factor $\mathrm{A}, \mathrm{x}_{2}$ is the variable that represents the factor $\mathrm{B}$, and $\varepsilon$ is the term that represents the random error. The variables $\mathrm{x}_{1}$ and $\mathrm{x}_{2}$ are defined in a coded scale from -1 to +1 (equivalent to levels "low" and "high" of the factors $\mathrm{A}$ and $\mathrm{B}$ ) and $\mathrm{x}_{1} \mathrm{x}_{2}$ is the interaction between $\mathrm{x}_{1}$ and $\mathrm{x}_{2}$.

For the experiment in figure 4 , the main effects of $\mathrm{A}$ and $\mathrm{B}$ are $\mathrm{A}=21$ and $\mathrm{B}=11$. The estimates of $\beta_{1}$ and $\beta_{2}$ are half the value of the effects corresponding main, i.e., $\beta_{1}=$ $21 / 2=10.5$ and $\beta_{2}=11 / 2=5.5$, so the interaction effect in Figure 4 , can be calculated as: 


$$
A B=\frac{52+20}{2}-\frac{40+30}{2}=1
$$

\section{(Equation 8).}

So, the interaction coefficient value in the regression model is $\beta_{12}=1 / 2=0.5$. The parameter $\beta_{o}$ is estimated by the average of four responses, as described below:

$$
\hat{\beta}_{0}=\frac{20+40+30+52}{4}=35.5
$$

\section{(Equation 9).}

Then, the regression model adjusted is:

$$
\hat{y}=35.5+10.5 x_{1}+5.5 x_{2}+0.5 x_{1} x_{2}
$$

(Equation 10).

\subsubsection{Factorial Planning - 2 Factors}

This 2-factor factorial design is the simplest factorial design, has only two factors or set of combinations, where there are $a$ levels of the factor $\mathrm{A}$ and $b$ levels of the factor $\mathrm{B}$, organized using factorial design. In general there are $n$ replicas, so each replica of the experiment contains all $a b$ combinations.

Considering a general case, where $\mathrm{y}_{i j k}$ will be the response variable when the factor $\mathrm{A}$ is at level $i(i=1,2, \ldots, a)$ and factor $\mathrm{B}$ is on the level $j(j=1,2, \ldots, b)$ at the replica $k(k=1,2, \ldots, n)$. In general, a factorial experiment with 2 factors follows a standard format as shown in Table 2. The order in which abn observations are considered is random selected, making this a completely random design. [5]

\begin{tabular}{c|c|c|c|c|}
\multicolumn{4}{c}{1} & \multicolumn{2}{c|}{$\ldots$} \\
\hline $\begin{array}{c}y_{111}, y_{112}, \ldots, \\
y_{11 n}\end{array}$ & $\begin{array}{c}y_{121}, y_{122}, \ldots, \\
y_{12 n}\end{array}$ & & $\begin{array}{c}y_{1 b 1}, y_{1 b 2}, \ldots, \\
y_{1 b n}\end{array}$ \\
\cline { 2 - 5 } & $\begin{array}{c}y_{211}, y_{212}, \ldots, \\
y_{21 n}\end{array}$ & $\begin{array}{c}y_{221}, y_{222}, \ldots, \\
y_{22 n}\end{array}$ & & $\begin{array}{c}y_{2 b 1}, y_{2 b 2}, \ldots, \\
y_{2 b n}\end{array}$ \\
\hline & & & & \\
\hline & $y_{a 11}, y_{a 12}, \ldots$, \\
$y_{a 1 n}$ & $y_{a 21}, y_{a 22}, \ldots$, & & $y_{a b 1}, y_{a b 2}, \ldots$, \\
$y_{a 2 n}$ & & $y_{a b n}$ \\
\hline
\end{tabular}

Table 2 - General Arrangement of a factorial design 2-factors

Observations in a factorial experiment can be described by a model. There are several ways to write this model, one of them, called the model effect, can be written as it follows: 


$$
y_{i j k}=\mu+\tau_{i}+\beta_{j}+(\tau \beta)_{i j}+\varepsilon_{i j k}\left\{\begin{array}{l}
i=1,2, \ldots, a \\
j=1,2, \ldots, b \\
k=1,2, \ldots, n \text { (Equation 11). }
\end{array}\right.
$$

So $\mu$ is the main medium effect, $\tau_{\mathrm{i}}$ is the effect level $i$ of the line of factor $\mathrm{A}, \beta_{j}$ is the effect of level $j$ of column of factor $\mathrm{B},(\tau \beta) i j$ is the interaction effect between $\tau_{\mathrm{i}}$ and $\beta_{j}$ and $\varepsilon_{i j k}$ is the component of random error. The two factors are considered fixed and the observations are defined as average main deviations:

$$
\begin{aligned}
& \sum_{i=1}^{a} \tau_{i}=0 \quad \text { (Equation 12). } \\
& \sum_{j=1}^{b} \beta_{j}=0 \quad \text { (Equation 13). }
\end{aligned}
$$

So, the interaction effects are fixed and defined as:

$$
\sum_{i=1}^{a}(\tau \beta)_{i j}=\sum_{j=1}^{b}(\tau \beta)_{i j}=0
$$

(Equation 14).

There are $n$ replicas in the experiment, so there are a total of $a b n$ informations.

Another possible model for a factorial experiment is the model of the medium that can be written:

$$
y_{i j k}=\mu_{i j}+\varepsilon_{i j k}\left\{\begin{array}{l}
i=1,2, \ldots, a \\
j=1,2, \ldots, b \\
k=1,2, \ldots, n
\end{array}\right. \text { (Equation 15). }
$$

Where the average ij cells can be defined as:

$$
\mu_{i j}=\mu+\tau_{i}+\beta_{j}+(\tau \beta)_{i j} \text { (Equation 16). }
$$

Besides the models presented, we can also use regression models as shown in Equation 7.But regression models are useful when one or more factors in the experiment are quantitative.

\subsubsection{Factorial Planning $-2^{k}$}

Usually, if there are k-factors, each of them with two levels, the factorial design will have $2^{\mathrm{k}}$ combinations. Factorial designs $2^{\mathrm{k}}$ type are extremely useful at the beginning of a product development when is necessary to investigate several factors and the researcher does not have enough experience to say if all of these factors are either not relevant to the experiment. This type 
of arrangement provides the fewest combinations where each $\mathrm{k}$ factor can be evaluated in a factorial design.

This kind of experiment allows the researcher study qualitative and quantitative factors, due to present only two levels for each factor, it assumes that the response variables have linear behavior.

Let's suppose that in a experiment we have three factors, each of them with two levels. In this case, we have an arrangement with the type $2^{3}$ with 8 combinations. These combinations can be graphically represented according to Figure 7. [3]
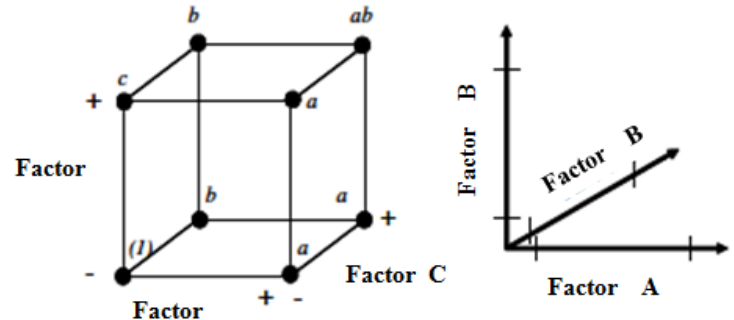

\section{Figure 7 - Representation of a factorial experiment $2^{3}$}

Using the "+" rating and "-" to represent the high and low levels respectively, we list the eight possible combinations of the arrangement $2^{3}$ according to the table 3 . This representation is usually called matrix planning or design matrix. Usually the following representation of combinations is: (1), $a, b, a b, c, a c, b c$ and $a b c$. Three different notations are widely used to identify the combinations in factorial designs $2^{\mathrm{k}}$. The first, "+" and "-" is called geometric notation. The second mentioned using lowercase already mentioned and finally the notation that uses 1 or 0 to represent the high and low levels of factors respectively, replacing the signs "+" and "-". These three different notations may also be observed in Table 3. [5]

\begin{tabular}{|c|c|c|c|c|c|c|c|}
\hline Combination & A & B & C & Representation & A & B & C \\
\hline 1 & - & - & - & $(1)$ & 0 & 0 & 0 \\
\hline 2 & + & - & - & $a$ & 1 & 0 & 0 \\
\hline 3 & - & + & - & $b$ & 0 & 1 & 0 \\
\hline 4 & + & + & - & $a b$ & 1 & 1 & 0 \\
\hline 5 & - & - & + & $c$ & 0 & 0 & 1 \\
\hline 6 & + & - & + & $a c$ & 1 & 0 & 1 \\
\hline 7 & - & + & + & $b c$ & 0 & 1 & 1 \\
\hline 8 & + & + & + & $a b c$ & 1 & 1 & 1 \\
\hline
\end{tabular}

\section{Table 3 - Planning Matrix and general notations factorial experiment $2^{3}$}

Obviously, if the number of factors of interest increases, so does the number of necessary combinations. For instance an experiment with 10 factors, with all the factors with two levels each, the number of combinations would be $2^{10}=$ 1024. Experiments like this one become impractical from the viewpoint of time to gather data and allocated resources. If there are five, six or more factors normally it is unnecessary to use all possible combinations between levels. In this case, the factorial experiment fractionated, or a variation of the complete experiment (full factorial) where only a fraction of the combinations is used, it is very useful.[1] 


\subsection{Response Surface Methodology (RSM)}

This is a set of design of experiments techniques for better understanding and optimization of response variables. The Response Surface Methodology (RSM) is commonly used to refine models obtained from factorial experiments, especially if during the development process of the experiment, the researcher suspected that certain factors may present a behavior like a curve, that means a nonlinear behavior. [4]

The difference between an equation that follows the response surface design and an equation that follows a factorial design is the addition of quadratic or cubic terms which allow the researcher also model surfaces that have curvature. On a surface response, let's suppose that the response variable $y$ will be analyzed due to two factors, $\mathrm{x}_{1}$ and $\mathrm{x}_{2}$. The Equation 17 represents this experiment. [5]

$$
y=f\left(x_{1}, x_{2}\right)+\varepsilon \text { (Equation 17). }
$$

Where $\varepsilon$ is the noise or error observed in answer y. Indicating that the expected response by:

$$
E(y)=f\left(x_{1}, x_{2}\right)=\eta \text { (Equation 18). }
$$

Then, the surface represented by: $\eta=f\left(x_{1}, x_{2}\right)$ (Equation 19).

It's called Response Surface.

\section{METHODOLOGY}

In this item presents a practical application of the Design of experiments (DoE), that was developed using a response surface method, in a 3.0L diesel engine, which the following characteristics - see table 4 .

\begin{tabular}{|c|c|}
\hline Combustion type & Compression lgnition \\
\hline Fuel & Diesel \\
\hline Number of strokes & 4 \\
\hline Volumetric capacity & $3.0 \mathrm{~L}$ \\
\hline Number of cylinders and arrangement & 4 - inline \\
\hline Cylinder head configuration & 4 valve SOHC \\
\hline Fuel Injection system & Eletronic with HPP and piezo injectors. \\
\hline Air inlet supply & Turbocharger with wastegate valve \\
\hline
\end{tabular}

Table 4 - Characteristics of the engine used in this work.

The methodology applied was the DoE technique, as explained in item 1 of this paper, determining the maximum allowable tolerances from diesel engine parts that interact with performance and emissions of it. These parts sources were from worldwide markets - the diesel fuel injection system from Germany supplier source, the turbocharger from China supplier source and the cylinder head gasket, engine synchronism and injector washers 
from Brazilian supplier sources. So the performance and emissions targets would be kept for serial production of the engine, as described below:

Performance: 88,5kw@3800rpm and 240N.m@1400-2600rpm (+/- 5\% production tolerance)

Emissions: China III emissions standard - similar to Euro III ( values must be between the gap below the legislation targets, with values near engineering targets) - see table 5 .

\begin{tabular}{|c|c|c|}
\cline { 2 - 3 } \multicolumn{1}{c|}{} & Engineering targets & Legislation targets \\
\hline E.E.NOx $(\mathbf{g} / \mathbf{k w} . \mathbf{h})$ & 4,80 & 5,00 \\
\hline E.E CO $(\mathbf{g} / \mathbf{k w} \cdot \mathbf{h})$ & 1,70 & 2,10 \\
\hline EE HC $(\mathbf{g} / \mathbf{k w} \cdot \mathbf{h})$ & 0,45 & 0,66 \\
\hline MIRA $(\mathbf{g} / \mathbf{k w} \cdot \mathbf{h})$ & 0,09 & - \\
\hline P.M. $(\mathbf{g} / \mathbf{k w} \cdot \mathbf{h})$ & 0,11 & 0,13 \\
\hline
\end{tabular}

Table 5 - China III emission legislation targets and margin for emissions.

In this experiment five factors with three levels for each factor were used, remembering that one of the levels was the central point, the factors are listed below:

$>\mathrm{x}_{1}$ - Fuel Injector - Hydraulic Flow (30ml/30sec)

$>\mathrm{x}_{2}$ Engine Synchromesh $\left({ }^{\circ} \mathrm{CRK}\right)$

$>\mathrm{x}_{3}$-Fuel Injector - Nozzle Tip Protrusion (NTP) $-(\mathrm{mm})$

$>\mathrm{x}_{4-}$ Cylinder head gasket thickness $-(\mathrm{mm})$

$>\mathrm{x}_{5}$ - Turbocharger - wastegate valve actuator position $-(\mathrm{mm})$

With Minitab 15 software the combinations were generated, the software suggests 54 combinations with 8 central points, but the researcher has the option to work with more or less central points depending on the interests (timing schedule, costs and accuracy)[4]. Besides allowing a quadratic analysis of response variables as a function of one more degree of freedom to the experiment, central points also allows the researcher check dynamometer operator repeatability and even more important the variability in the measurements done due to equipments utilized like in gaseous emissions - the emissions benches and in the case of fuel consumption, the fuel meter gadgets. Due to time schedule and limited resources a fractioned experiment was selected with 30 combinations and 4 central points, typically if we attribute to levels "low" and "high" the -1 and +1 notation respectively, and 0 notation to central points, the experiment can be created as shown in table 6 . 


\begin{tabular}{|c|c|c|c|c|c|c|c|}
\hline StdOrder & RunOrder & PtType & $\mathrm{x} 1$ & $\mathrm{x} 2$ & $\mathrm{x} 3$ & $\mathrm{x} 4$ & $\mathrm{x} 5$ \\
\hline 10 & 1 & 1 & 1 & -1 & -1 & 1 & 1 \\
\hline 15 & 2 & 1 & -1 & 1 & 1 & 1 & -1 \\
\hline 18 & 3 & -1 & 1 & 0 & 0 & 0 & 0 \\
\hline 30 & 4 & 0 & 0 & 0 & 0 & 0 & 0 \\
\hline 8 & 5 & 1 & 1 & 1 & 1 & -1 & -1 \\
\hline 29 & 6 & 0 & 0 & 0 & 0 & 0 & 0 \\
\hline 3 & 7 & 1 & -1 & 1 & -1 & -1 & -1 \\
\hline 9 & 8 & 1 & -1 & -1 & -1 & 1 & -1 \\
\hline 14 & 9 & 1 & 1 & -1 & 1 & 1 & -1 \\
\hline 16 & 10 & 1 & 1 & 1 & 1 & 1 & 1 \\
\hline 12 & 11 & 1 & 1 & 1 & -1 & 1 & -1 \\
\hline 1 & 12 & 1 & -1 & -1 & -1 & -1 & 1 \\
\hline 26 & 13 & -1 & 0 & 0 & 0 & 0 & 1 \\
\hline 6 & 14 & 1 & 1 & -1 & 1 & -1 & 1 \\
\hline 4 & 15 & 1 & 1 & 1 & -1 & -1 & 1 \\
\hline 23 & 16 & -1 & 0 & 0 & 0 & -1 & 0 \\
\hline 28 & 17 & 0 & 0 & 0 & 0 & 0 & 0 \\
\hline 20 & 18 & -1 & 0 & 1 & 0 & 0 & 0 \\
\hline 22 & 19 & -1 & 0 & 0 & 1 & 0 & 0 \\
\hline 13 & 20 & 1 & -1 & -1 & 1 & 1 & 1 \\
\hline 27 & 21 & 0 & 0 & 0 & 0 & 0 & 0 \\
\hline 2 & 22 & 1 & 1 & -1 & -1 & -1 & -1 \\
\hline 11 & 23 & 1 & -1 & 1 & -1 & 1 & 1 \\
\hline 7 & 24 & 1 & -1 & 1 & 1 & -1 & 1 \\
\hline 19 & 25 & -1 & 0 & -1 & 0 & 0 & 0 \\
\hline 21 & 26 & -1 & 0 & 0 & -1 & 0 & 0 \\
\hline 5 & 27 & 1 & -1 & -1 & 1 & -1 & -1 \\
\hline 24 & 28 & -1 & 0 & 0 & 0 & 1 & 0 \\
\hline 17 & 29 & -1 & -1 & 0 & 0 & 0 & 0 \\
\hline 25 & 30 & -1 & 0 & 0 & 0 & 0 & -1 \\
\hline
\end{tabular}

Table 6 - Matrix of design of experiments type response surface, for 5 factors (fractioned) generated by Minitab 15 software.

For the factors $\mathrm{x}_{1}, \mathrm{x}_{2}, \mathrm{x}_{3}, \mathrm{x}_{4}$ and $\mathrm{x}_{5}$ already mentioned, some levels were considered, as shown on table 7 :

\begin{tabular}{|c|c|c|c|c|c|c|}
\hline \multirow{2}{*}{ Factor } & \multirow{2}{*}{ Description } & \multirow{2}{*}{ Nickname } & \multirow{2}{*}{ Unit } & \multicolumn{3}{|c|}{ Level } \\
\hline & & & & -1 & 0 & 1 \\
\hline $\mathbf{x 1}$ & Fuel Injector - Hydraulic Flow & Injetor & $(30 \mathrm{ml} / 30 \mathrm{sec})$ & 490 & 500 & 510 \\
\hline$x 2$ & Engine Synchromesh & Sincro & ( CRK) & 12 & 15 & 18 \\
\hline $\mathbf{x 3}$ & $\begin{array}{l}\text { Fuel Injector - Nozzle Tip Protrusion } \\
\text { (NTP) }\end{array}$ & NTP & $(\mathrm{mm})$ & 0,7 & 1,2 & 1,7 \\
\hline $\mathbf{x} 4$ & Cylinder head gasket thickness & Junta & $(\mathrm{mm})$ & 1,3 & 1,4 & 1,5 \\
\hline$x 5$ & $\begin{array}{l}\text { Turbocharger - wastegate valve } \\
\text { actuator position }\end{array}$ & Atuador & $(\mathrm{mm})$ & 1 & 1,5 & 3 \\
\hline
\end{tabular}

Table 7 - General data of design of experiments for manufacturability factors - 3.0L engine.

The output (response varaibles) of the DoE experiment and its units:

$\mathrm{NOx}$ - concentration of NOx pollutants in $\mathrm{g} / \mathrm{kw} . \mathrm{h}$

$\mathrm{CO}$ - concentration of $\mathrm{CO}$ pollutants in $\mathrm{g} / \mathrm{kw} . \mathrm{h}$

$\mathrm{HC}$ - concentration of $\mathrm{HC}$ pollutants in $\mathrm{g} / \mathrm{kw} . \mathrm{h}$

The output (response variables) of the DoE experiment: (cont.)

MIRA - correlation factor to estimate the particulate matter (PM) in $\mathrm{g} / \mathrm{kw} . \mathrm{h}$

Power - in $\mathrm{kW}$

Torque - in N.m

During data acquisition some boundary conditions like speed, torque, T22 (air temperature after the intercooler), P1 (inlet restriction), P4 (exhaust backpressure 
restriction), temperature and relative humidity of intake air, temperature and pressure of inlet diesel fuel and battery voltage must be kept fixed with extremely reduced tolerances to minimize noises in the measurements.

Defined the design and matrix of the experiment, the boundary conditions and limits to be respected, the data gathering starts on steady state dynamometer in the same sequence as the matrix was generated by the Minitab software. Normally in a engine combustion development experiment a lot of response variables like T3 (exhaust gas temperature), fuel consumption, combustion pressure (pz), NOx (nitrogen oxides) emissions, smoke, cooling temperature, etc. are gathered, due to academic purposes just some response variables are shown.

After running the experiments, the next step of the process of planning design of experiments is performed, the statistics analysis of the gathered data, that can be done using several statistics software like Minitab and Matlab. The analysis presented here were generated using Minitab 15 software.

\section{RESULTS}

As explained in item 1 of this work, a graphical analysis type Main Effects was performed, presenting first the results of the factors analysis in individual form related to response variables, without taking into account the interaction effects - see figure 8 .

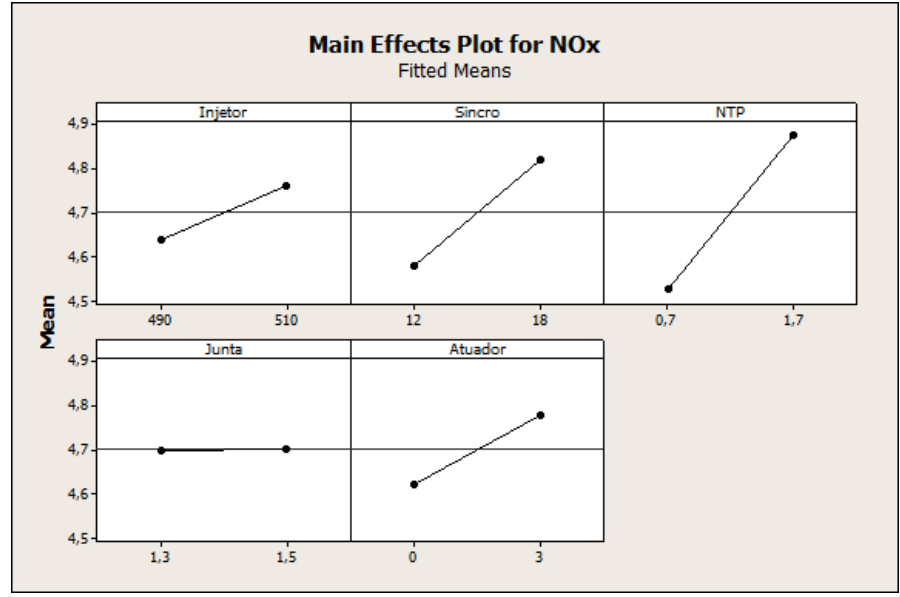

Figure 8 - Graphical analysis Main Effects type for NOx response variable.

Figure 8 shows that from the 5 factors, four of them have effect on the NOx emissions, with the biggest inclinations in relation to the average line for NTP and engine synchromesh factors respectively. The "junta" factor seems not to change the engine compression ratio, as far as the NOx doesn't change considerably with this factor, according to figure 8. Its well known that when compression ratio increases considerably the NOx levels increases due to temperature increase during combustion.

In figure 9 the main effects for $\mathrm{CO}$ and $\mathrm{HC}$ emissions can be seen, the same tendency of four from the five factors have biggest effect on response variables, in this case the "Junta" shows bigger influence then "Atuador" for CO and HC against the opposite tendency as seen for NOx. The other three factors "Injetor", "Sincro" and NTP kept with major influence on emissions. 

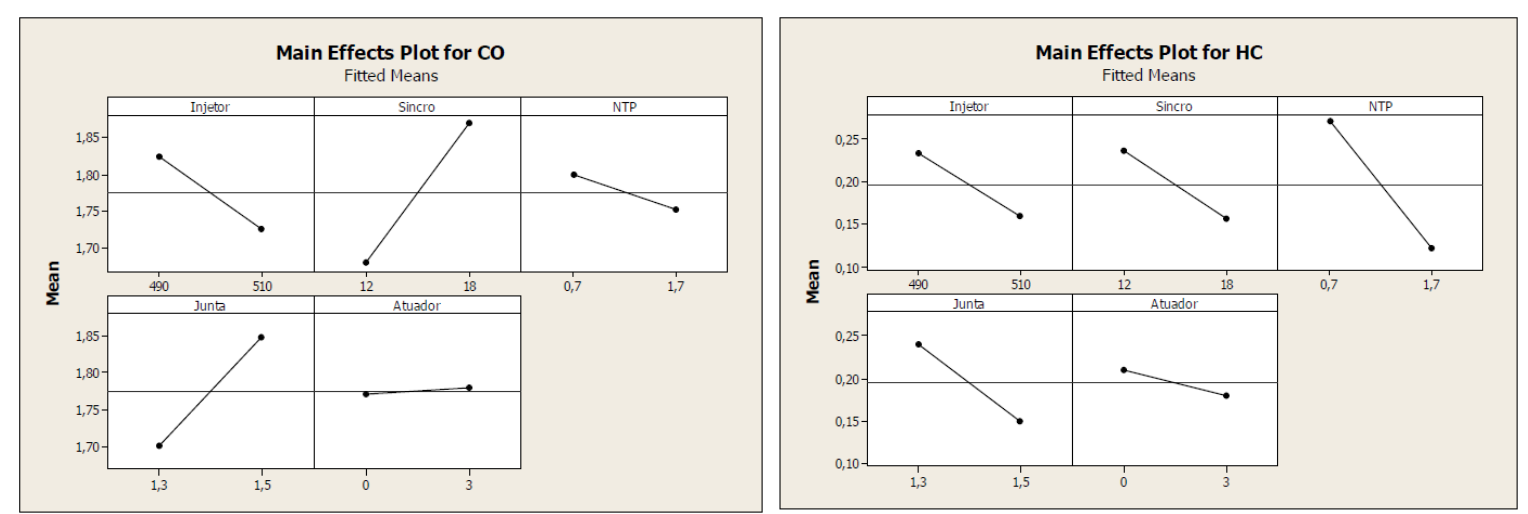

Figure 9 - Graphical analysis Main Effects type for $\mathrm{CO}$ and $\mathrm{HC}$ response variables.

In figure 10 the main effects for MIRA response are shown, a big effect on soot formation is noticed due to injector protrusion (NTP), this converges with the fact that soot formation is dependent on spray break up and how the spray cone interacts with the combustion bowl.

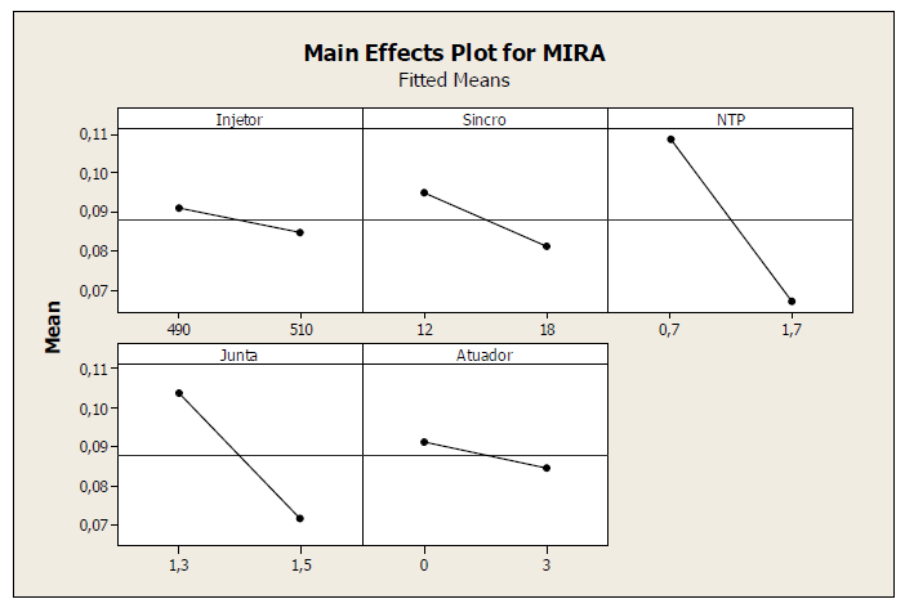

Figure 10 - Graphical analysis Main Effects type for MIRA response.

At this point of analysis, the tendency of the graphs indicates that a reduction on the production variation of this parts (factors) will reduce the variation on output emissions (response variables).

For Power and Torque response variables, illustrated on figure 11, we can see that "Junta" variable plays some role in power output, this small effect on compression ratio appears only in power condition (high engine speed), in torque region @ 2000rpm condition the tendency is near the same illustrated on figure 8. This converges to the fact that the speeds 2347rpm, 2946rpm and 3545rpm used in ESC cycle to measure emissions, are lower than max power speed $-3800 \mathrm{rpm}$, and are near torque region (until 2600rpm). This shows another advantage of the DoE tool also helps to indentify some slightly particular effects of the parts on engine behavior. Also in this figure notice that "Injector" that represents the Hidraulic Flow of the fuel injectors plays a major role on power and torque variables as expected and well known in diesel engines development. 

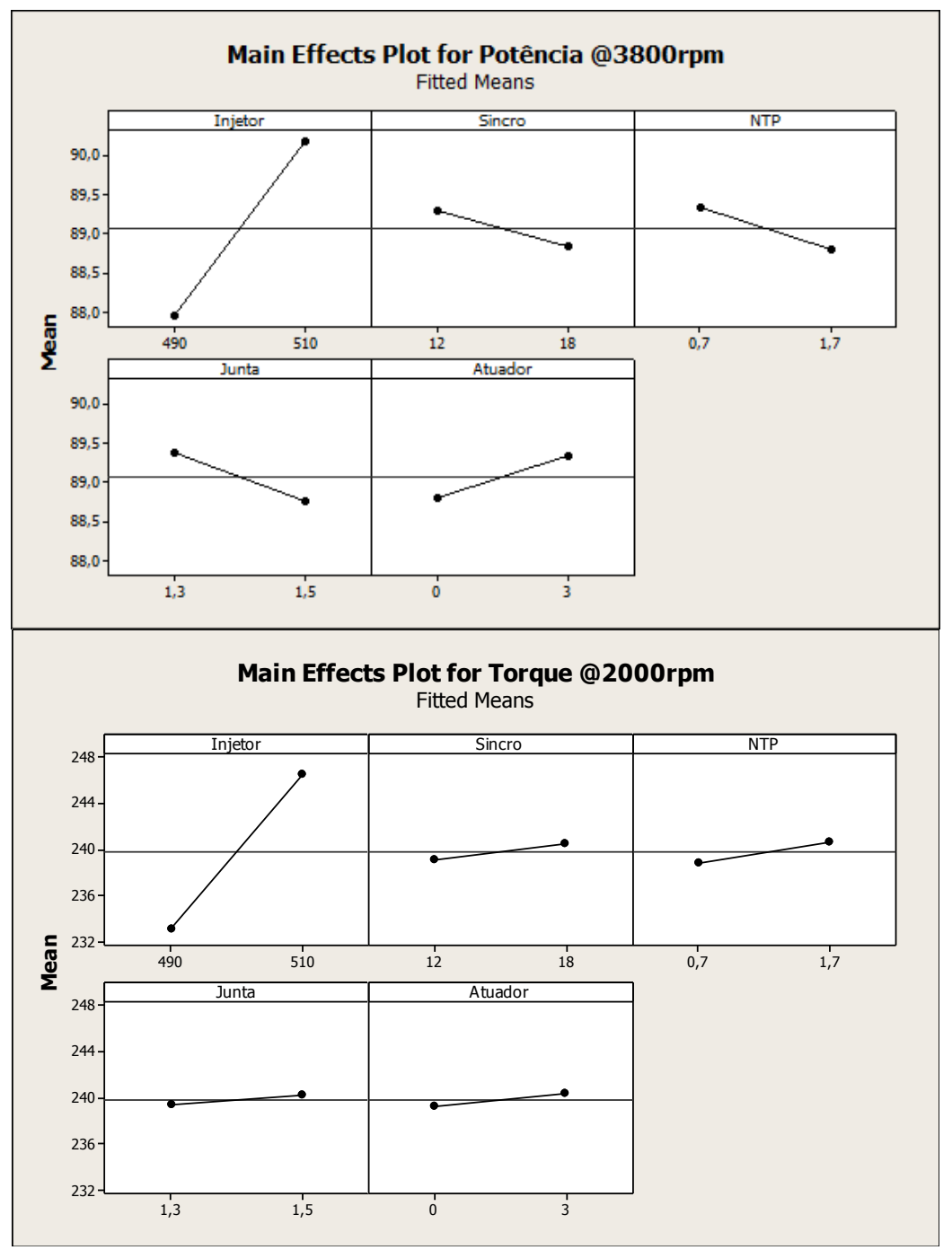

Figure 11 - Graphical analysis Main Effects type for Power and Torque responses.

Now going to Interaction Plot graphical analysis, where the interaction effects between two factors compared to the response variable. For each combination the values of the response variable NOx - in the case of figure 12 - are plotted related to the existing scale on the right side of the matrix on figure 12 , for levels -1 and +1 of each factor.

There is interaction between two factors when the change in the mean value of the response variable from level -1 to level +1 of a factor depends on some level of other factor. If the red and black lines on figure 12 are parallel it means that there's no interaction between the factors, in other words the change in the average value of the response variable from level -1 to level +1 of a given factor doesn't depend of any level of the other factor. In the case of non-parallel lines there is interaction between the factors under analysis. 


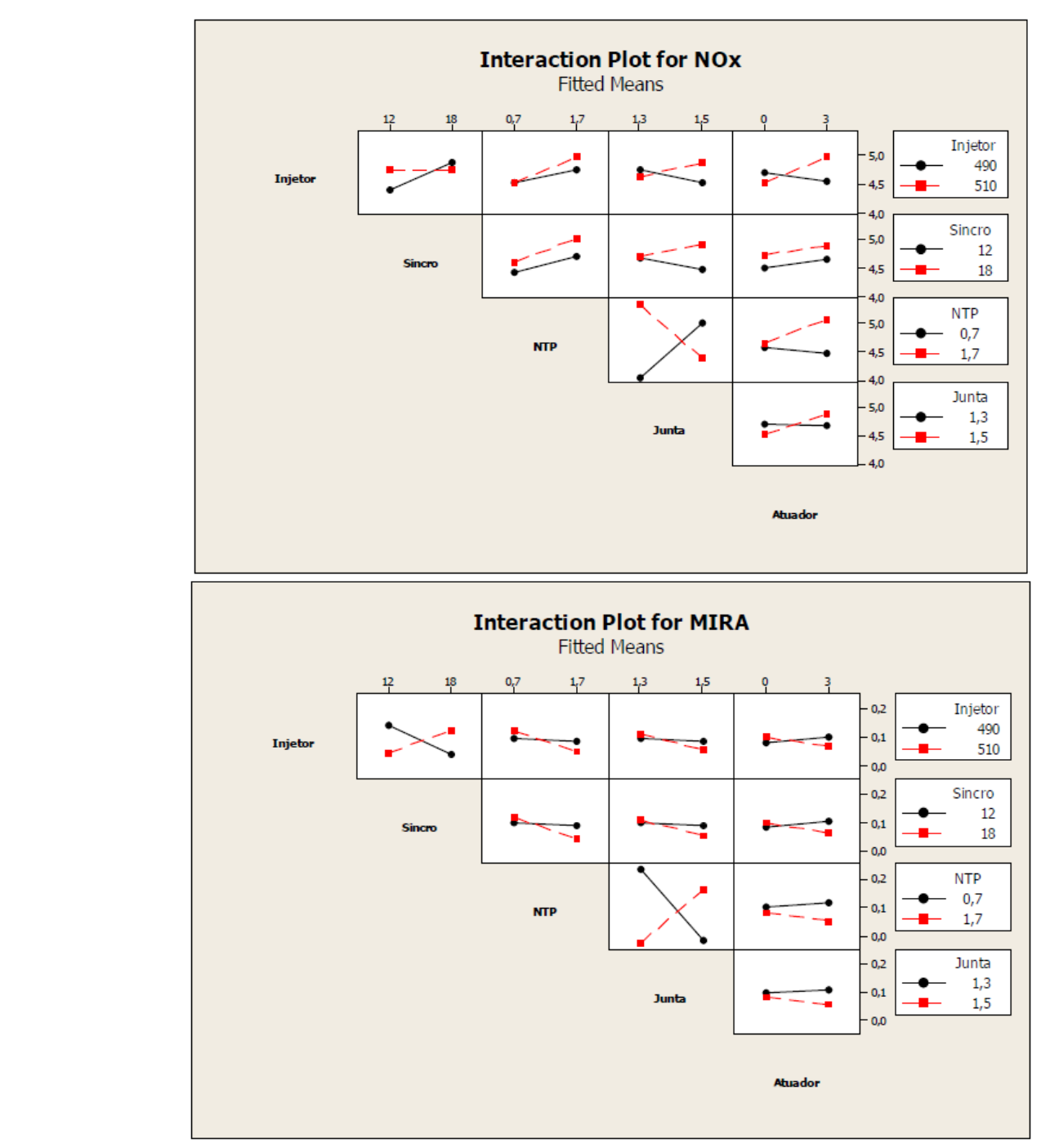
Figure 12 - Graphical analysis Interaction Plot type for NOx and MIRA responses
variables.

The response optimizer analysis is the latest and best step on statistics analysis showing how the different levels adopted in the design factors - i.e. parts production tolerances affects the Power, Torque, and gaseous emissions (NOx, CO, HC, MIRA) response variables. In this kind of analysis the researcher can input the values to be minimized, maximized or target of the response variables, then based on the model generated the software calculates an optimized solution with graphical analysis as shown on figures 13 and 14 .

This is only part of the response optimizer analysis, the researcher can also change the levels of the factors according to objective of it. Figures 13 and 14 also show the representation of levels -1 and +1 of the utilized factors on the experiment in black and the values of the current configuration in red. The analysis shows the effect of each factor ( $y-$ axis direction) under the response variables in study ( $\mathrm{x}$ - axis direction). This figures 13 and 14 also show the importance of controlled and reduced manufacturing tolerances in engine components to avoid huge variations on its performance and emissions. 


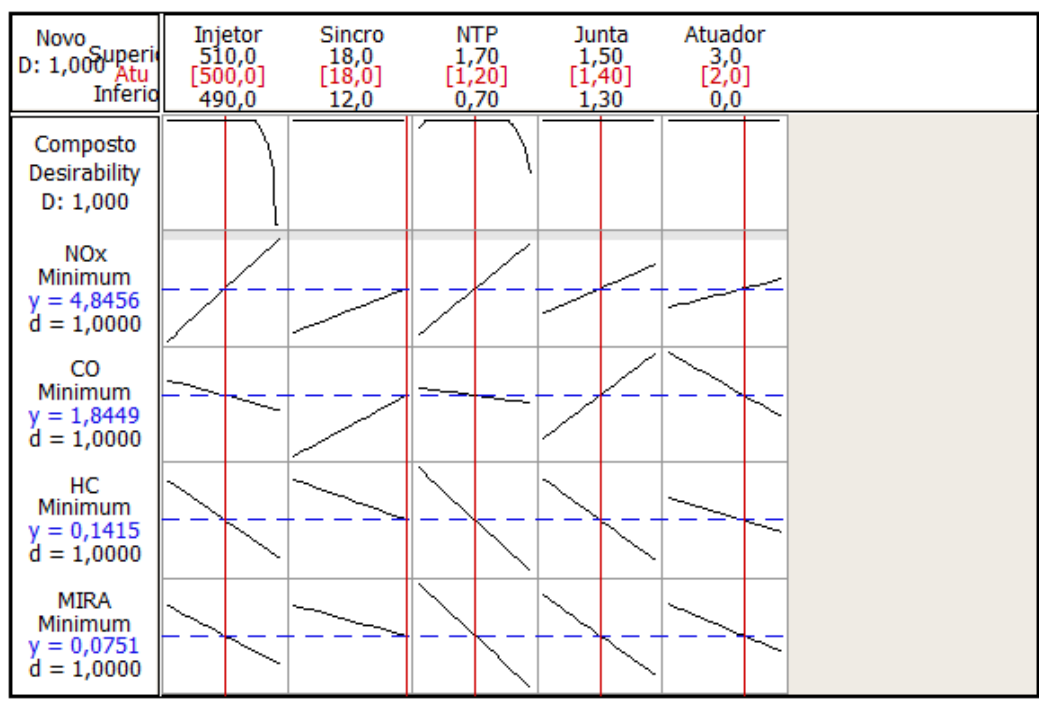

Figure 13 - Graphical response optimizer analysis for emissions response variables.

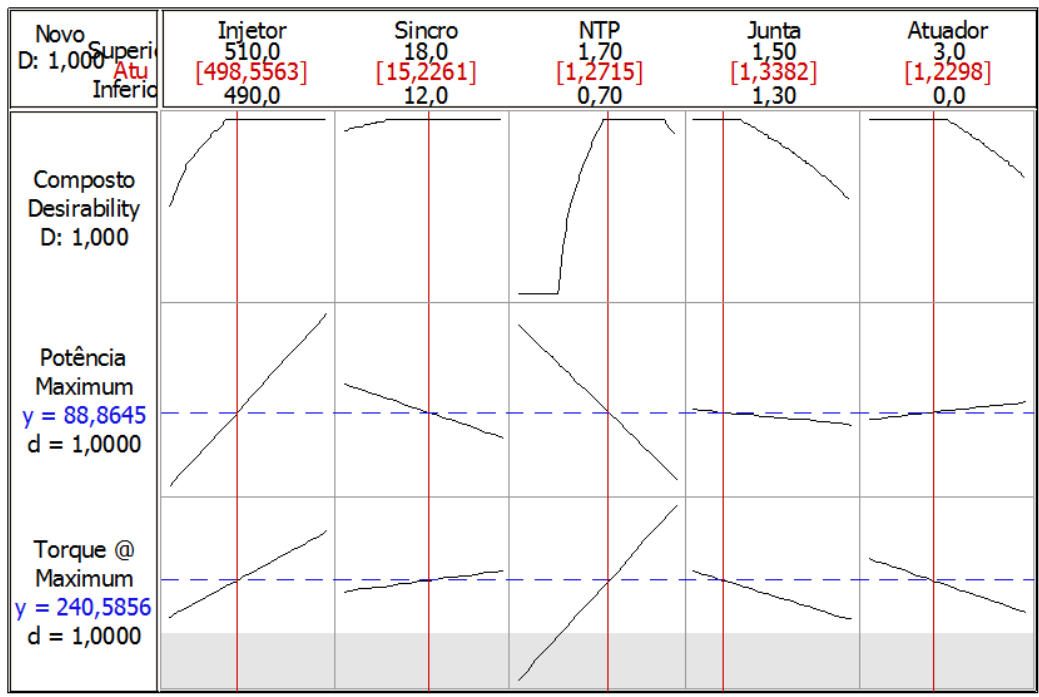

Figure 14 - Graphical response optimizer analysis for Power and Torque performance - response variables.

After this the models generated, the coefficients in uncoded units were transferred to Excel to generate the plan with the simulation of engine emissions control on production. The random values were generated in Microsoft Excel by RAND () function based on Monte Carlo mathematical series.

The best tolerances for the engine parts involved in this study were found after a three step changes in tolerances of all components, looking for an output inside the emissions and performance targets for a population of $99,7 \%$, or six sigma. ( + and -3 sigma for each side of the normal curve distribution) - considering 1000 engines sample size to generate the random values.(it means 1000 random values generated by Excel function - RAND)

FIRST STEP - The first step to find the best production tolerances for engine parts or hardware matching the emissions and performance targets was done with the standard 
production tolerances of all the components of the hardware involved in this study, results were below the expected confidence of 99,7\%. See figure 15 .

Tolerances inputted to generate the 1000 random tests :

\begin{tabular}{|c|c|c|c|c|c|c|c|c|c|c|c|c|}
\hline & $\begin{array}{l}\text { Fuel Injector } \\
\text { Hydraullc } \\
\text { Flow }\end{array}$ & $\begin{array}{l}\text { Cyllnder } \\
\text { Head } \\
\text { Gasket }\end{array}$ & $\begin{array}{c}\text { Fuel Injector } \\
\text { High }\end{array}$ & $\begin{array}{l}\text { Engine Static } \\
\text { Syncromesh }\end{array}$ & $\begin{array}{l}\text { Turbocharger } \\
\text { Actuator }\end{array}$ & & Nox & $\mathrm{CO}$ & $\mathrm{HC}$ & MIRA & Power & Torque \\
\hline & $\begin{array}{l}\mathrm{ml} 30 \mathrm{seg} \\
\text { (ब100bar }\end{array}$ & $\mathrm{mm}$ & $\mathrm{mm}$ & degrees & $\mathrm{mm}$ & & $g / k W h$ & $g / k W h$ & $g / k W h$ & $g / k W h$ & kW & $\mathrm{Nm}$ \\
\hline Máx. & 510 & 1,5 & 1,2 & 18 & 3 & Máx. & 5 & 2,1 & 0,66 & 0,13 & 92,4 & 254,4 \\
\hline Min. & 490 & 1,3 & 0,7 & 12 & 1 & Min. & $-\overline{-}$ & -- & -- & - & 83,6 & 225,6 \\
\hline
\end{tabular}

Statistical Results:

\begin{tabular}{|c|r|r|r|r|r|r|}
\hline Mean & 4,627891 & 1,801125 & 0,226024 & 0,097534 & 89,23464 & 239,4267 \\
\hline Deviation & 0,25422 & 0,128659 & 0,194336 & 0,055584 & 1,093848 & 7,839066 \\
\hline +2 Sigma & 5,136331 & 2,187103 & 0,809034 & 0,264286 & 92,51619 & 262,9439 \\
\hline -2 Sigma & 4,119451 & 1,415147 & $-0,356985$ & $-0,069218$ & 85,9531 & 215,9095 \\
\hline +3 Sigma & 5,390551 & 2,573081 & 1,392043 & 0,431039 & 95,79773 & 286,461 \\
\hline -3 Sigma & 3,865231 & 1,029169 & $-0,939994$ & $-0,23597$ & 82,67156 & 192,3923 \\
\hline
\end{tabular}

Figure 15 - Table for FIRST STEP simulation using random values.

SECOND STEP- The second step was done reducing all the tolerances, less the injector hydraulic flow, the results are better but MIRA, Power and Torque values - in red - are out of the boundaries for the confidence of $99,7 \%$ in a population of 1000 engines. See figure 16.

\begin{tabular}{|c|c|c|c|c|c|c|c|c|c|c|c|c|}
\hline & $\begin{array}{l}\text { Fuel Injector } \\
\text { Hydraullc } \\
\text { Flow }\end{array}$ & $\begin{array}{l}\text { Cyllnder } \\
\text { Head } \\
\text { Gasket }\end{array}$ & $\begin{array}{c}\text { Fuel Injector } \\
\text { Hlgh }\end{array}$ & $\begin{array}{l}\text { Engine Statid } \\
\text { Syncromesh }\end{array}$ & $\begin{array}{l}\text { Turbocharger } \\
\text { Actuator }\end{array}$ & & Nox & $\mathrm{CO}$ & $\mathrm{HC}$ & MIRA & Power & Torque \\
\hline & $\begin{array}{l}\mathrm{ml} 30 \mathrm{seg} \\
\text { (1000ar }\end{array}$ & $\mathrm{mm}$ & $\mathrm{mm}$ & degrees & $\mathrm{mm}$ & & $g / k W h$ & g/kWh & g/kWh & $g / k W h$ & kW & $\mathrm{Nm}$ \\
\hline Máx & 510 & 1,4 & 1,4 & 15 & 2 & Máx. & 5 & 2,1 & 0,66 & 0,13 & 92,4 & 254,4 \\
\hline Min & 490 & 1,3 & 1,2 & 14 & 1 & Min. & -- & -- & -- & - & 83,6 & 225,6 \\
\hline
\end{tabular}

Statistical Results:

\begin{tabular}{|c|r|r|r|r|r|r|}
\hline Mean & 4,787959 & 1,742569 & 0,158868 & 0,078696 & 89,03556 & 241,4541 \\
\hline Deviation & 0,058285 & 0,022555 & 0,042092 & 0,009975 & 0,667661 & 3,614224 \\
\hline +2 Sigma & 4,904528 & 1,810234 & 0,285145 & 0,108621 & 91,03854 & 252,2968 \\
\hline -2 Sigma & 4,67139 & 1,674905 & 0,032591 & 0,048771 & 87,03258 & 230,6114 \\
\hline +3 Sigma & 4,962813 & 1,877898 & 0,411423 & 0,138546 & 93,04153 & 263,1395 \\
\hline -3 Sigma & 4,613106 & 1,60724 & $-0,093686$ & 0,018846 & 85,02959 & 219,7688 \\
\hline
\end{tabular}

Figure 16 - Table for SECOND STEP simulation using random values.

THIRD STEP - The third step was done reducing the hydraulic flow and fuel injector high (NTP) tolerances, and releasing the engine synchromesh tolerance (due to production limitations) reaching values according to the targets of emissions and performance with a confidence of $99,7 \%$ for a population fo 1000 engines. See figure 17.

Tolerances inputted:

\begin{tabular}{|c|c|c|c|c|c|c|c|c|c|c|c|c|}
\hline & $\begin{array}{c}\text { Fuel Injector } \\
\text { Hydraullc } \\
\text { Flow }\end{array}$ & $\begin{array}{l}\text { Cyllnder } \\
\text { Head } \\
\text { Gasket }\end{array}$ & NTP & $\begin{array}{l}\text { Engine Static } \\
\text { Syncromesh }\end{array}$ & $\begin{array}{l}\text { Turbocharger } \\
\text { Actuator }\end{array}$ & & Nox & $\mathrm{CO}$ & $\mathrm{HC}$ & MIRA & Power & Torque \\
\hline & $\begin{array}{l}\text { mV/30seg } \\
@ 100 \text { bar }\end{array}$ & $\mathrm{mm}$ & $\mathrm{mm}$ & degrees & $\mathrm{mm}$ & & $g / k W h$ & g/kWh & g/kWh & $g / k W h$ & kW & $\mathrm{Nm}$ \\
\hline Máx. & 505 & 1,4 & 1,3 & 16 & 2 & Máx. & 5 & 2.1 & 0,66 & 0,13 & 92,4 & 254,4 \\
\hline Min. & 495 & 1,3 & 1,2 & 14 & 1 & Min. & $=$ & $=$ & $=$ & $=$ & 83,6 & 225,6 \\
\hline
\end{tabular}

Statistical Results: 


\begin{tabular}{|c|r|r|r|r|r|r|}
\hline Mean & 4,738318 & 1,748286 & 0,189659 & 0,088011 & 89,1305 & 240,3412 \\
\hline Deviation & 0,038717 & 0,033311 & 0,024023 & 0,006319 & 0,36962 & 1,901822 \\
\hline +2 Sigma & 4,815753 & 1,848221 & 0,261729 & 0,106967 & 90,23936 & 246,0467 \\
\hline -2 Sigma & 4,660884 & 1,648352 & 0,117589 & 0,069054 & 88,02164 & 234,6357 \\
\hline +3 Sigma & 4,85447 & 1,948155 & 0,333799 & 0,125924 & 91,34822 & 251,7521 \\
\hline -3 Sigma & 4,622167 & 1,548418 & 0,045518 & 0,050097 & 86,91278 & 228,9303 \\
\hline
\end{tabular}

Figure 17 - Table for THIRD STEP simulation using random values.

\section{CONCLUSIONS}

Combining statistics tools as DoE and its analysis with RSM, with the use of RAND functions from excel was possible predict the performance and emissions behavior with production parts on its regular tolerances, and was recommended to reduce some of then, in this case considering the characteristics of each production process of each component or assembly: the fuel injector due to a more accurate and precise method of production has its tolerances reduced. For cylinder gasket due to three different thickness available, one of the extremes was removed ( $1,5 \mathrm{~mm}$ factor) based on all the analysis performed, the NTP due to measurements done in engine cylinder head was controlled in the band of $1,2 \mathrm{~mm}$ to $1,3 \mathrm{~mm}$ with its tolerances reduced using a $2,0 \mathrm{~mm}$ injector washer. The engine synchromesh and turbo actuator variables are both related to assembling processes and its tolerances, so both were kept on its original tolerances due to process complexity to reduce both. So the recommended tolerances for 3.0L engine for reaching the emissions (Euro III / China III standards) and performance targets with a confidence of 99,7\% (6 sigma) in a population of engines are illustrated on figure 18:

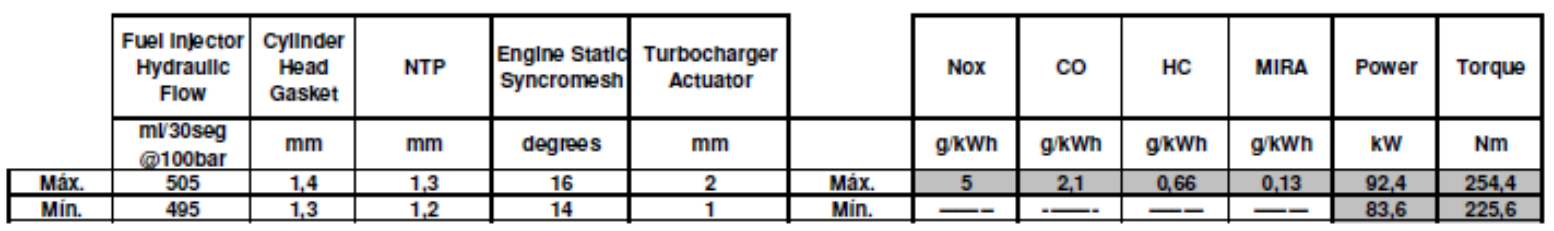

Figure 18 - Table with the final result for components tolerances for 3.0L engine.

\section{REFERENCES}

[1] LOURENÇO, Álvaro A.M.; SPERL, André; PORCINO, Leandro P. O Emprego de Ferramentas Estatísticas de Modelamento no Desenvolvimento de Combustão em Motores Diesel - Paper SAE Brasil - 2008-36-0103. São Paulo-SP: SAE, 2008.

[2] VERLAG MODERNE INDUSTRIE. DoE - Design of Experiments - methods and applications in engine development. Berlin: IAV GmbH, 2005.

[3] G. E. P. Box and D. W. Behnken. Some New Three Level Designs for the Study of Quantitatives Variables. Technometrics, 1960.

[4] FDG - Fundação de Desenvolvimento Gerencial. Apostila Introdução ao Software Minitab for Windows - Versão 13. São Paulo-SP: FDG, 2004.

[5] D. C. Montgomery. Design and Analysis of Experiments, 5th Edition. New York: John Wiley \& Sons, 2001. 